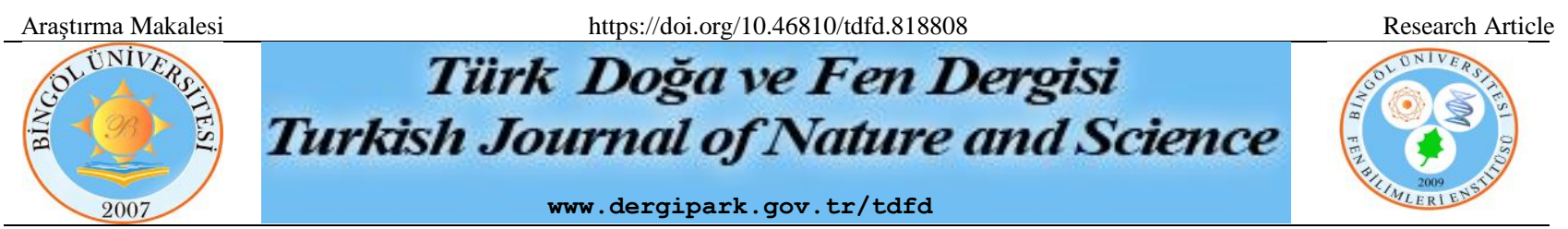

\title{
Yeni Antrasen Bazlı Kopolimer Sistemi ve Grafen Kompozitlerinin Hazırlanması, Termal ve Elektriksel Özelliklerinin İncelenmesi
}

\author{
Fatih BİRYAN ${ }^{1 *}$ \\ ${ }^{1}$ Fırat Üniversitesi, Fen Fakültesi, Kimya Bölümü, Elazığ, Türkiye \\ Fatih BIRRYAN ORCID No: 0000-0001-9198-3329 \\ *Sorumlu yazar: fatihbiryan@gmail.com
}

(Alınış: 02.11.2020, Kabul: 18.11.2020, Online Yayınlanma: 30.12.2020)

\begin{abstract}
Anahtar
Kelimeler

Kopolimer,

Grafen

kompozit,

Termal

davranış,

Dielektrik,

Elektriksel

özellikler

Öz: $\mathrm{Bu}$ çalışma, antrasen içeren kalkon yan zincirli yeni kopolimer sisteminin termal ve elektriksel özelliklerini incelemeyi amaçlamıştır. Monomer ve kopolimerlerin yapıları FT-IR, ${ }^{1} \mathrm{H}-$ NMR ve ${ }^{13} \mathrm{C}$-NMR teknikleri kullanılarak karakterize edildi. Kopolimerlerin termal davranışları DSC ve TGA kullanılarak analiz edildi. Kopolimerdeki antrasen birimlerinin artmasıyla camsı geçiş sıcaklığının $123{ }^{\circ} \mathrm{C}^{\prime}$ den $142{ }^{\circ} \mathrm{C}^{\prime}$ ye yükseldiği gözlemlendi. Kopolimer matriksine \% 4 grafen partikülleri ilave edilerek yarı-iletken kompozitler hazırlandı. Kopolimerlerin ve grafen kompozitlerinin dielektrik ölçümleri $100 \mathrm{~Hz}-20 \mathrm{kHz}$ frekans aralığında empedans analizör tekniği kullanılarak incelendi. P(MMA-ko-AAPAc 0.43)'nn dielektrik sabiti grafenin ilavesiyle 5.21'den 273.28'e yükseldi. Kompozitlerin aktivasyon enerjisi değerleri, sıcaklığın bir fonksiyonu olarak DC iletkenliği ölçülerek elde edildi. Aktivasyon enerjisi değerleri P(MMA-ko-AAPAc 0.16), P(MMA-ko-AAPAc 0.31) ve P(MMA-ko-AAPAc 0.43) için sırasılyla 0.320, 0.077 ve $0.040 \mathrm{eV}$ olarak belirlendi.
\end{abstract}

\section{Preparation of New Anthracene Based Copolymer System and Graphene Composites, Investigation of Thermal and Electrical Properties}

\section{Keywords Copolymer, Graphene composite, Thermal behaviour, Dielectric, Electrical properties}

\begin{abstract}
This study aimed to investigate the thermal and electrical behavior of the new copolymer system with chalcone side chain containing anthracene. The structures of monomer and copolymers were characterized using FT-IR, ${ }^{1} \mathrm{H}-\mathrm{NMR}$ and ${ }^{13} \mathrm{C}-\mathrm{NMR}$ techniques. The thermal behaviors of copolymers have been analyzed by using DSC and TGA. The glass transition temperature was increased from $123{ }^{\circ} \mathrm{C}$ to $142{ }^{\circ} \mathrm{C}$ with increasing the anthracene content in the copolymer. Semiconducting composites of copolymers have been prepared by adding $4 \%$ graphene particles to the copolymer matrix. The dielectric measurements of the copolymers were investigated using the impedance analyzer technique in the frequency range of $100 \mathrm{~Hz}-20 \mathrm{kHz}$. The dielectric constant is greatly increase from 5.21 to 273.28 for P(MMA-co-AAPAc 0.43 ) by the addition of $4 \%$ nanographene. The AC and DC conductivity of copolymer/graphene composites were measured. Furthermore, the activation energy values of the copolymer/4\% graphene composites were obtained by measuring the $\mathrm{DC}$ conductivity as a function of temperature. The activation energy values of the copolymer/4\% graphene composites were 0.320 , 0.077 and $0.040 \mathrm{eV}$ for P(MMA-co-AAPAc 0.16), P(MMA-co-AAPAc 0.31) and P(MMA-coAAPAc 0.43), respectively.
\end{abstract}

\section{GİRIŞ}

Antrasen yan yana dizilmiş benzen halkalarından dolayı 14 delokalize elektronları ile genişletilmiş $\pi$-konjuge sisteme sahiptir. Antrasen üç aromatik halka içermesi, fotofiziksel ve benzersiz özellikleri sayesinde polimer bilimindeki birçok uygulamada uzun süredir çalışılmaktadır [1]. Atrasen konjuge yapısı kolay elektron haraketliliği sağladığından organik transistörler [2-4] ve OLED uygulamaları için ilgi çekici olmuştur [5-
6]. Polimer yapısındaki antrasenin çarpıcı özelliklerini daha iyi anlamak için, metil metakrilat (MMA) gibi reaktif fonksiyonel gruplar içermeyen bir monomerle kopolimerlerinin hazırlanması faydalı olacaktır. Bu durumda, polimerizasyon sirasında büyüyen tekrar eden birimlerin antrasen ile etkileşime girmemesi önemlidir, çünkü bu polimer yapısının bozulmasına (ek dallanma, çapraz bağlanma) neden olabilir, bu da yapısal değişiklikleri tetikler ve dolayısıyla optik özellikleri değiştirir. MMA ana monomer olarak kullanıldığında, serbest radikal polimerizasyonu sirasında MMA'yı 
polimerizasyon sistemine katarak büyüyen makromolekülün antrasen grubu ile etkileşime girdiği düşünülemez [7]. Daha önce yapılmış bir çalışmada MMA ile kopolimerizasyon için antrasen içeren bir monomer olarak 9-vinil antrasen kullanılmıştır [8]. Vinil grubunun a-karbon atomunun sterik etkisi sebebiyle polimerin dönüşümü ve molekül ağırlığı düşük kalmış ayrıca kopolimerdeki antrasen konsantrasyonu monomer karışımındakinden daha düşük olmuştur [9].

Bu çalışmada, antrasen halkası içeren bir hidroksi kalkon bileşiği ve bunun akriloil klorür ile reaksiyonu sonucunda yeni bir monomer sentezlenmesi amaçlandi. Ayrica bu yeni monomer ile yapıdaki sterik engeli azaltmayı ve polimerizasyonu daha aktif hale getirmeyi hedefledik. Böylece yüksek konjugasyona sahip antrasen içeren kalkon grubunun kopolimerindeki konsantrasyon artışının termal ve elektriksel özellikler üzerindeki etkisi araştırıldı.

Polimerin yapısındaki konjugasyon ve polar fonksiyonel gruplar, dielektrik sabiti üzerinde önemli bir etkiye sahiptir. Dielektrik özellikler alternatif akıma (AC) bağlı olarak $100 \mathrm{~Hz}$ ve $20 \mathrm{kHz}$ frekans aralığında farklı sıcaklıklarda ölçüldü. Ayrıca kopolimerlerin ön denemelerinden sonra \%4 grafen kompozitleri hazırlandı. Yarı iletken özellik göstermesi amaçlanan polimer grafen kompozitlerinin AC iletkenliğine ek olarak, DC iletkenlik ölçümleri de sıcaklığın bir fonksiyonu olarak ölçüldü ve aktivasyon enerjileri hesaplandi.

\section{MATERYAL VE METOT}

4-hidroksibenzaldehit, 9-asetil antrasen, akriloil klorür, metil metakrilat, sodyum hidroksit, tetrahidrofuran (THF), dimetilformamid (DMF), trietilamin $\left(\mathrm{Et}_{3} \mathrm{~N}\right)$, başlatıcı olarak kullanılan dikumil peroksit (DCP) ve etil alkol Sigma-Aldrich'ten temin edildi. Polimer kompozitlerin hazırlanmasında kullanılan nanografen $(\%$ 99.9, 5nm) Nanografi'den temin edilmiștir.

FT-IR spektrumları için Perkin-Elmer Spectrum One FTIR spektroskopisi kullanıldı. Monomer spektrumu $\mathrm{KBr}$ ile pelleti, kopolimer spektrumları $\mathrm{NaCl}$ penceresi yüzeyinde ince filmi hazırlanarak kaydedildi. NMR spektrumları AVANCE III $400 \mathrm{MHz}$ Bruker NMR spektrometresi ile ölçülmüştür. NMR analizi için $500 \mu \mathrm{L}$ döteryum çözücülerinde ( $\mathrm{d}_{6}$-DMSO veya $\mathrm{d}$-kloroform) yaklaşık $20 \mathrm{mg}$ numune çözündürüldü. GPC ölçümleri için $1 \mathrm{~mL} /$ dakikalık bir akış hızında tetrahidrofuran (THF) çözücüsü ve kalibrasyon için standart polistiren kullanıldı

Polimer ve polimer kompozitlerinin termal analizleri, TGA ve DSC teknikleri kullanılarak azot atmosferinde gerçekleştirildi. TGA ve DSC analizleri için sırasıyla Shimadzu TGA-50 ve DSC-50 modelleri kullanıldı. TGA analizleri $5 \mathrm{mg}$ numuneler kullanilarak oda sıcaklığından $600{ }^{\circ} \mathrm{C}$ 'ye $10{ }^{\circ} \mathrm{C} / \mathrm{dk}$ isıtma hızında, DSC analizleri ise $20 \mathrm{mg}$ numuneler kullanılarak oda sicaklığından $200 \quad{ }^{\circ} C^{\prime}$ ye $20 \quad{ }^{\circ} \mathrm{C} / \mathrm{dk} \quad$ 1sitma hizında kaydedilmiştir. Polimer kompozitlerin dielektrik karakterizasyonu için, numuneler (yaklaşık $100 \mathrm{mg}$ ) 5 bar basınç altında peletler halinde oluşturulmuştur.

Dielektrik özellikler, HIOKI IM3536 LCR metre ile oda sıcaklığında $100 \mathrm{~Hz}-20 \mathrm{kHz}$ frekans aralığında ölçüldü. Polimer/grafen kompozitin DC iletkenliği ve I-V karakteristiği FYtronix Electric Characterization sistemi kullanılarak gerçekleştirildi. Kopolimerlerin ortalama molekül ağırlıkları bir vakumlu gaz giderici ve bir kırılma indisi detektörü ile donatılmış Agilent 1100 sistemine sahip yüksek basınçlı bir sıvı kromatografi pompası kullanılarak gerçekleştirildi.

\subsection{1-(Antrasen-9-il)-3-(4-hidroksifenil) prop-2-en-1- on (AHPP) Sentezi İçin Genel Yöntem (AHPP)}

1-(Antrasen-9-il)-3-(4-hidroksifenil) prop-2-en-1-on bileşiği (AHPP), 4-hidroksibenzaldehidin, 9-asetil antrasen ile literatürdeki şartlara göre reaksiyonu sonucu hazırlandı [10]. AHPP'nin sentezi Şema 1'de gösterilmektedir.

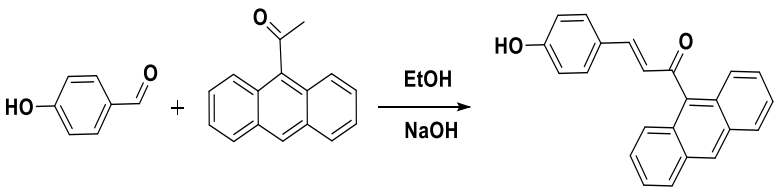

Şema 1. 1-(Antrasen-9-il)-3-(4-hidroksifenil) prop-2-en-1-on bileşiğinin sentez şeması (AHPP)

\subsection{4-(3-(antrasen-9-il) akriloil) fenil akrilat monomerin (AAPAc) Hazırlanması}

4-(3-(antrasen-9-il) akriloil) fenil akrilat monomeri (AAPAc), trietilamin varlığında 1-(Antrasen-9-il)-3-(4hidroksifenil) prop-2-en-1 ve akriloil klorür'ün reaksiyonu sonucu sentezlendi. Susuz tetrahidrofuran (THF) içinde hazırlanmış $0.87 \mathrm{~g}(9.71 \mathrm{mmol})$ akriloil klorür çözeltisi, $0-5{ }^{\circ} \mathrm{C}$ sicaklık arasında tetrahidrofuran içinde çözülmüş olan $3 \mathrm{~g}$ (9.25 mmol) AHPP ve $0.97 \mathrm{~g}$ (9.71 mmol) trimetilamin çözeltisine yavaş yavaş eklenmiştir. Daha sonra reaksiyon karışımı oda sıcaklığında 6 saat karıștırıldı. Elde edilen karıșım süzüldü ve suda çöktürüldü. Son olarak, monomer 24 saat vakum altında kurutuldu. Monomerin sentezi Şema 2 'de gösterilmektedir.

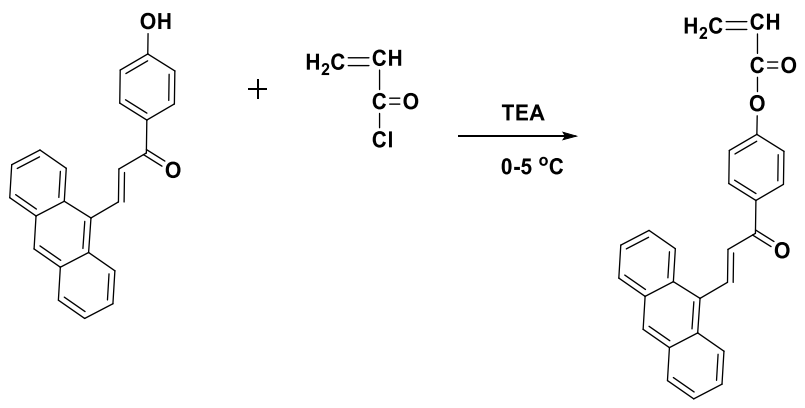

Şema 2. 4-(3-(antrasen-9-il) akriloil) fenil akrilat monomerin sentez șeması (AAPAc)

\subsection{Kopolimerlerin Hazırlanmas}

Poly (AAPAc-ko-MMA), THF çözücünde, $70{ }^{\circ} \mathrm{C}^{\prime} \mathrm{de} 48$ saat süreyle başlatıcı olarak DCP kullanılarak serbest 
radikal polimerizasyon (SRP) prosedürüne göre hazırlandı. Aynı koşullar altında, farklı mol oranlarında kopolimerler sentezlendi. Kopolimerler, etil alkol içinde çöktürülerek saflaştırıldı. Kopolimerler vakum altında 40 ${ }^{\circ} C^{\prime}$ de bir gün kurutuldu. Kopolimerin yapısı Şema 3 'te gösterilmektedir.

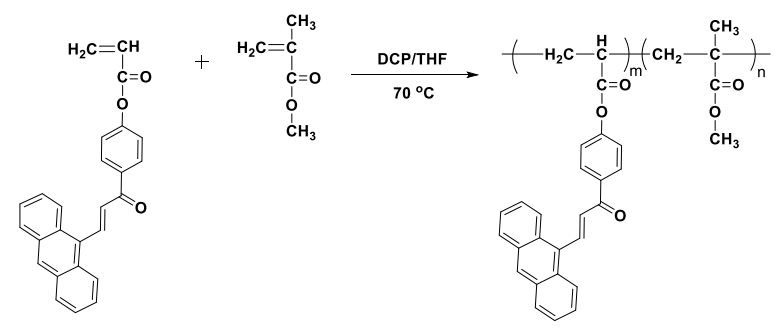

Şema 3. P(AAPAc-ko-MMA)'ın sentez şeması

Kopolimer sistemindeki MMA ve AAPAc'nin mol fraksiyonları, MMA birimleri için 3,63 ppm'de $-\mathrm{OCH}_{3}$ protonlarının sinyalinin integral yüksekliğinden ve 6,99 ile 8,64 ppm arasında AAPAc'deki aromatik protonların integral yüksekliklerinden belirlendi. Kopolimer sistemdeki monomer oranları aşağıdaki denkleme göre hesapland1:

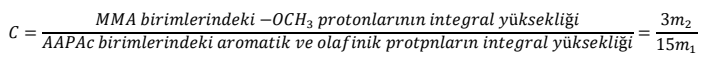

Kopolimerleri hazırlamak için başlangıçta kullanılan AAPAc ve MMA monomer bileşimleri ve integral yükseklikler Tablo 1'de özetlendi.

Tablo 1. Başlangıçta kullanılan AAPAc ve MMA monomer bileşimleri ve integral yükseklikleri

\begin{tabular}{|c|c|c|l|c|}
\hline \multirow{5}{*}{ AAPAc } & $\mathbf{M}_{\mathbf{1}}^{\mathbf{b}}$ & $\begin{array}{l}\text { AAPAc } \\
\text { birimlerindeki } \\
\text { aromatik ve } \\
\text { olefinik } \\
\text { protonların int. } \\
\text { yüksekliği }\end{array}$ & $\begin{array}{l}\text { MMA } \\
\text { birimlerindeki } \\
-\mathrm{OCH}_{3} \\
\text { protonlarının } \\
\text { integral } \\
\text { yüksekliği }\end{array}$ & $\mathbf{m}_{\mathbf{1}}^{\mathbf{c}}$ \\
\cline { 2 - 5 } & 0.15 & 1.13 & 3.0 & 0.07 \\
& 0.30 & 3.41 & 3.0 & 0.16 \\
& 0.50 & 6.80 & 3.0 & 0.31 \\
& 0.60 & 11.64 & 3.0 & 0.43 \\
\hline
\end{tabular}

$\mathrm{m}_{1}$ and $\mathrm{m}_{2}$ sirasıyla AAPAc ve MMA birimlerinin kopolimerdeki mol oranları

AAPAc ve MMA sisteminin başlangıç ve kopolimerindeki monomer bileşimi verileri Tablo 2'de verildi.

Tablo 2. Başlangıç ve kopolimerdeki monomer konsantrasyonu

\begin{tabular}{|c|c|c|c|c|}
\hline Polimer & \multicolumn{2}{|c|}{$\begin{array}{l}\text { Monomerin } \\
\text { bașlanglc mol }\end{array}$} & \multicolumn{2}{|c|}{$\begin{array}{l}\text { Monomerin } \\
\text { kopolimerdeki } \\
\text { mol oranı }\end{array}$} \\
\hline P(MMA-ko-AAPAc 0.07) & 0.15 & 0.85 & 0.07 & 0.93 \\
\hline P(MMA-ko-AAPAc 0.16) & 0.30 & 0.70 & 0.16 & 0.84 \\
\hline P(MMA-ko-AAPAc 0.31) & 0.50 & 0.50 & 0.31 & 0.69 \\
\hline P(MMA-ko-AAPAc 0.43) & 0.60 & 0.40 & 0.43 & 0.57 \\
\hline
\end{tabular}

$\mathrm{M}_{1}$ : AAPAc, $\mathrm{M}_{2}$ : MMA

\subsection{P(AAPAc-ko-MMA)/Grafen Kompozitlerinin Hazırlanması}

Kompozitleri hazırlamak için, önce tetrahidrofuran (THF) içinde çözülmüş poli(AAPAc-ko-MMA) üzerine kütlece $\% 4$ grafen eklenerek mekanik olarak karıştırıldı. Daha sonra, grafenin kopolimer matris içinde homojen dağılımı için yaklaşık 2 saat süreyle ultrasonik dispersiyona tabi tutuldu. Sonunda çözücü tamamen uzaklaştırıldı ve kompozitler gece boyunca vakum altında $40{ }^{\circ} \mathrm{C}^{\prime}$ de kurutuldu.

\section{BULGULAR}

\subsection{Karakterizasyon}

Monomerin FT-IR spektrumu (AAPAc) Şekil 1'de gösterilmektedir. AAPAc'nin ${ }^{1} \mathrm{H}-\mathrm{NMR}$ ve ${ }^{13} \mathrm{C}-\mathrm{NMR}$ spektrumları sirasıyla Şekil 2(a) ve Şekil 2(b) 'de verilmiştir. Monomerin (AAPAc) karakteristik pikleri aşağıdaki gibi özetlenmiştir:

FT-IR: (vmax, $\mathrm{cm}^{-1}$ ): 3055 (aromatik halkadaki $\mathrm{C}=\mathrm{C}-\mathrm{H}$ gerilme titreşimi), 2976-2858 (alifatik -C-H gerilmesi), 1744 (akrilat grubundaki ester $-\mathrm{C}=\mathrm{O}$ gerilmesi), 1640 (keton $\mathrm{C}=\mathrm{O}$ gerilmesi), 1621 (vinil grubundaki $-\mathrm{C}=\mathrm{C}$ gerilmesi), 1595 (aromatik halkadaki $\mathrm{C}=\mathrm{C}$ gerilmesi).

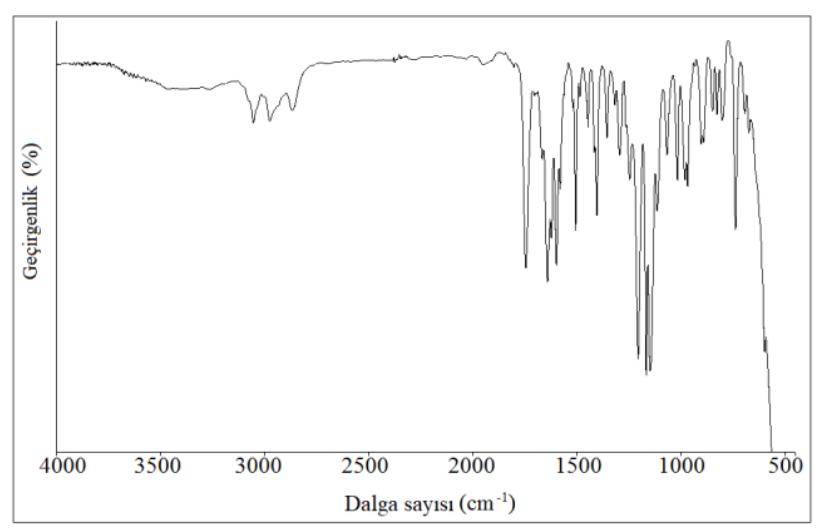

Şekil 1. Monomerin FT-IR spektrumu (AAPAc)

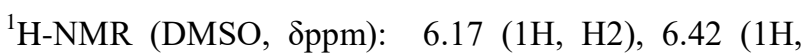
H3), 6.53 (1H, H1), 7.19 (2H, H4), 7.29 (1H, H6), 7.52 $(1 \mathrm{H}, \mathrm{H} 7), 7.58$ (4H, H9 ve H10), $7.76(2 \mathrm{H}, \mathrm{H} 5), 7.83$ (2H, H11), 8.22 (2H, H8), 8.79 (1H, H12)

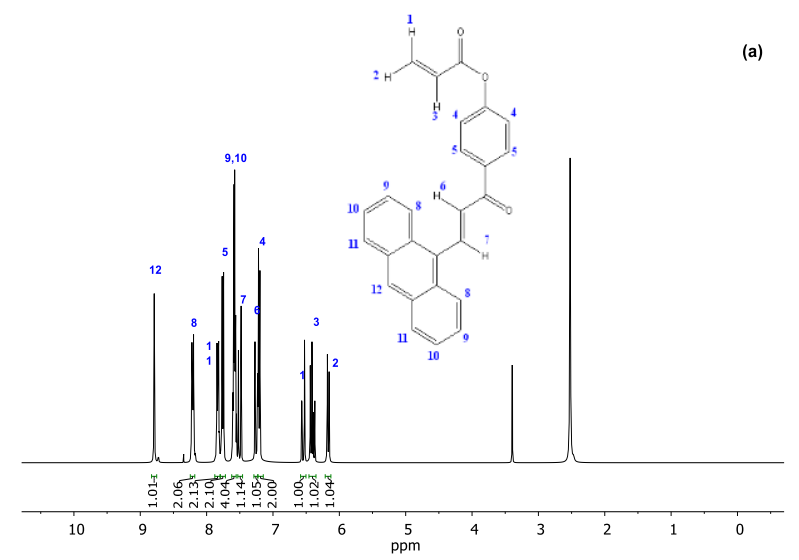




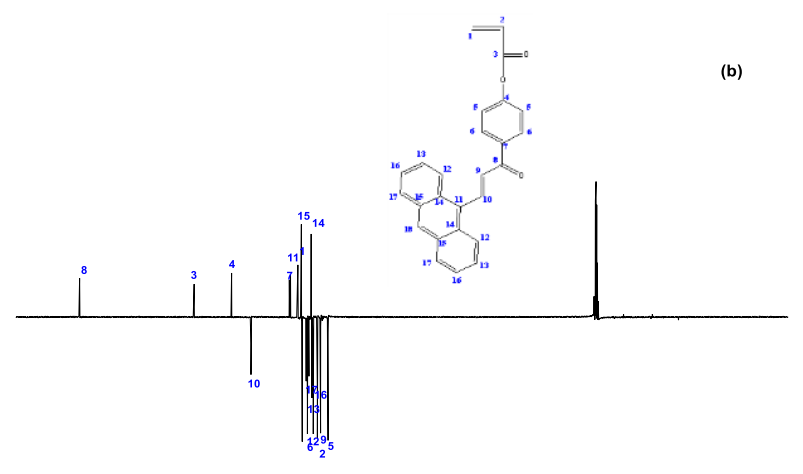

$\begin{array}{lllllllllll}1 & 1 & 1 & 1 & 1 & 1 & 1 & 1 & 1 & 1 & 1 \\ 100 & 140 & 120 & 100 & 80 & 60 & 40 & 20 & 0\end{array}$

Şekil 2. a) Monomerin ${ }^{1} \mathrm{H}$ ve b) ${ }^{13} \mathrm{C}$ NMR spektrumları (AAPAc)

${ }^{13} \mathrm{C}-\mathrm{NMR}$ (DMSO, 8ppm): 199.6 (C8), 164.3 (C3), 152.5 (C4), 146.7 (C10), 134.8 (C7), 134.5 (C11), 132.2 (C1), 131.0 (C15), 130.8 (C16), 129.6 (C2), 129.2 (C6), 128.7 (C13), 128.1 (C14), 127.9 (C17), 126.1 (C12), 125.1 (C9), 122.9 (C5), 121.2 (C18).

Ayrıca, yüksek çözünürlüklü kütle spektrumunda, m/z = 379.1346'daki pik monomerin moleküler iyonuna $\left[\mathrm{C}_{26} \mathrm{H}_{18} \mathrm{O}_{3}\right]^{+}(\% 100)$ atfedilir. Yüksek çözünürlüklü kütle spektrumu Şekil 3 'te gösterilmektedir.

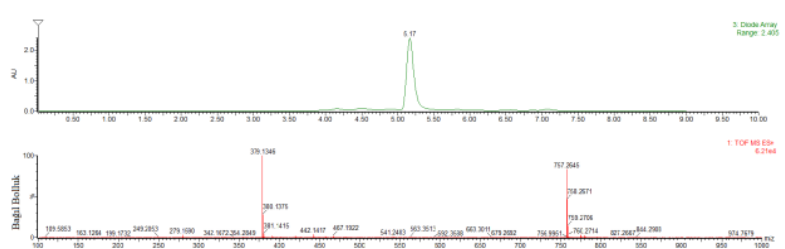

Şekil 3. Monomerin yüksek çözünürlüklü kütle spektrumu (HRMS)

P(MMA-ko-AAPAc) kopolimer serisinin FT-IR spektrumları karşılaştırmalı olarak Şekil 4'te gösterilmektedir. Karakteristik pikler; (vmax, cm-1): 3055 (AAPAc birimlerinde aromatik halka üzerindeki $\mathrm{C}=\mathrm{C}-\mathrm{H}),(1754$ (AAPAc birimlerinde ester $-\mathrm{C}=\mathrm{O}), 1730$ (MMA birimlerinde ester $-\mathrm{C}=\mathrm{O}$ ) , 1644 (AAPAc birimlerinde keton karbonili $-\mathrm{C}=\mathrm{O}$ ), 1595 (AAPAc birimlerinde aromatik halka üzerindeki $\mathrm{C}=\mathrm{C}$ ).

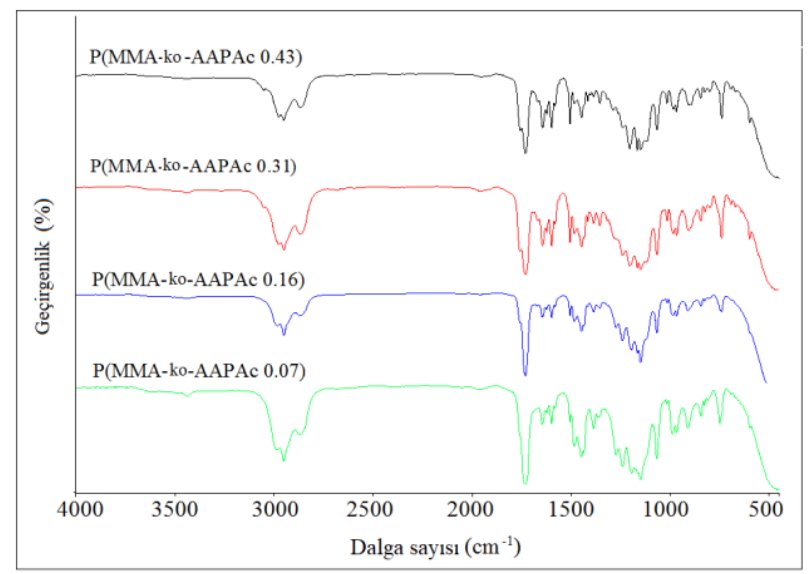

Şekil 4. P(MMA-ko-AAPAc) kopolimerlerinin FT-IR spektrumları

P(MMA-ko-AAPAc) kopolimer serilerinin ${ }^{1} \mathrm{H}-\mathrm{NMR}$ spektrumları Şekil 5'te verilmiştir. Ana zincirdeki alifatik protonlar ve MMA birimlerindeki $-\mathrm{CH}_{3}$ protonları 0.80 $2.01 \mathrm{ppm}$ aralığında gözlenmiştir. 3.62 ppm'de MMA birimlerindeki metoksi $\left(-\mathrm{CH}_{3} \mathrm{O}\right)$ protonları, 7.01-8.58 ppm aralığında AAPAc birimlerindeki aromatik protonlar gözlendi. Aromatik protonların sinyal yoğunluğu, kopolimerde artan AAPAc birimlerinin konsantrasyonu ile artmaktadir. P(MMA-ko-AAPAc $0.43)$ '1n ${ }^{13} \mathrm{C}-\mathrm{NMR}$ spektrumu Şekil 6'da verilmiştir. 200.1 ppm keton ( $\mathrm{C}=\mathrm{O}$ karbon), 177.8 ve 176.6 ppm sirasiyla MMA birimleri ve AAPAc birimlerinde ester karbonili en karakteristik sinyallerdir. Aromatik karbonlar, AAPAc birimlerinde 152.5-122.2 ppm aralığında gözlendi. 51.86 ppm'de MMA birimindeki metoksi karbonu, 44.5 ppm'de ana zincir karbonlar1, 18,13 ppm'de ana zincirdeki $-\mathrm{CH}_{3}$ karbonları gözlenmiştir.
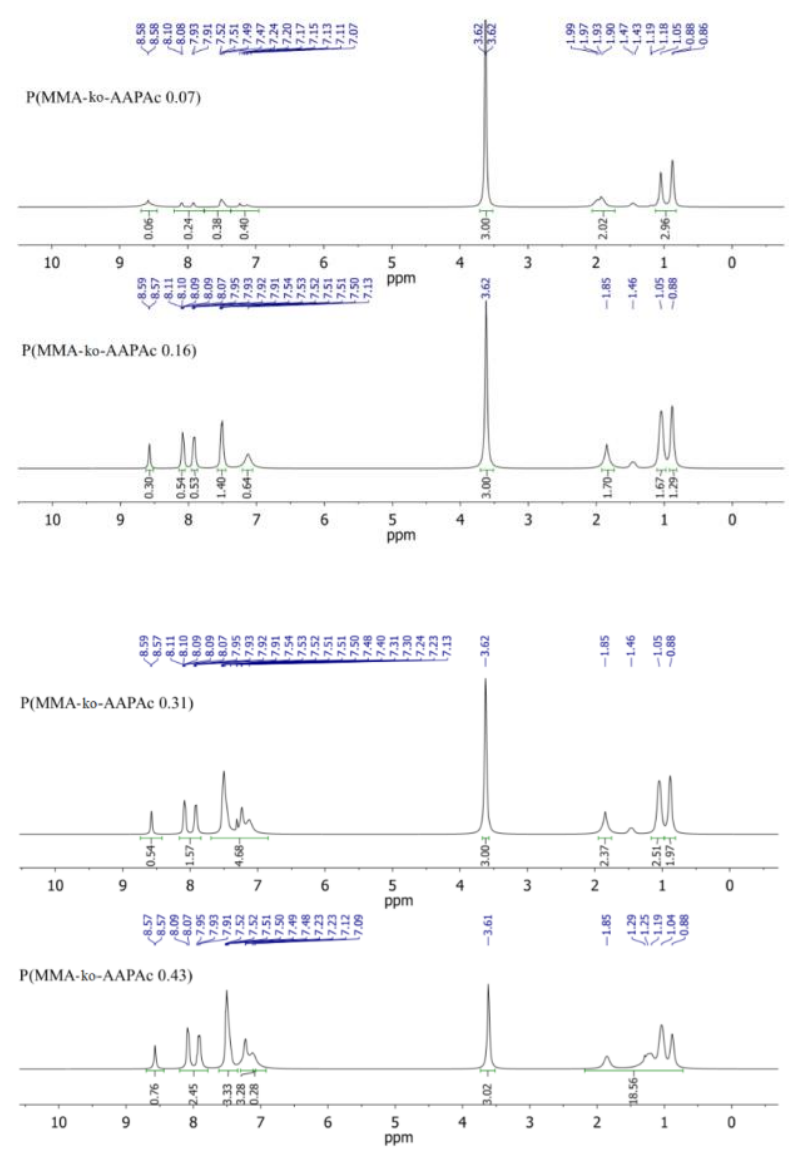

Şekil 5. P(MMA-ko-AAPAc) kopolimerlerinin ${ }^{1} \mathrm{H}-\mathrm{NMR}$ spektrumları

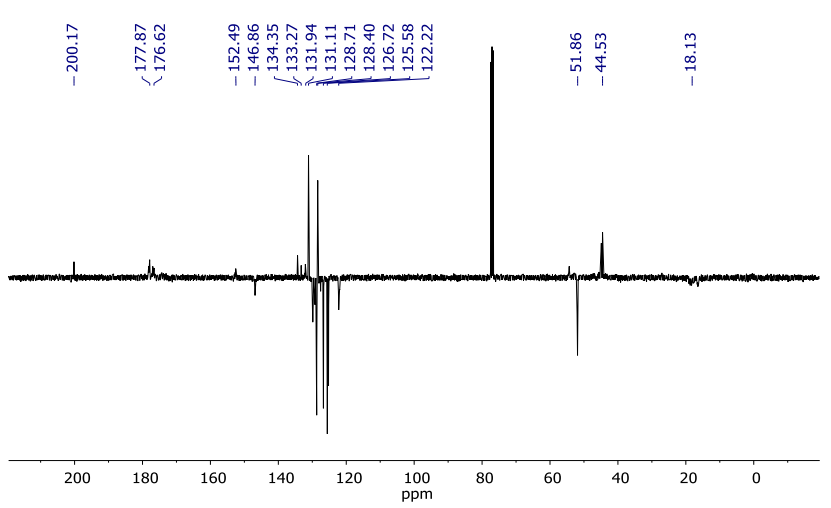

Şekil 6. P(MMA-ko-AAPAc 0.43 ) kopolimerin ${ }^{13}$ C-NMR spektrumu

Kopolimerlerin ortalama moleküler ağırlıkları, jel geçirgenlik kromatografisi ile belirlendi. Kalibrasyon için standart PSt ve çözücü olarak THF kullanıldı. 
Kopolimerler için polidispersite, sayıca $(\mathrm{Mn})$ ve ağırlıkça (Mw) ortalama (Mn) moleküler ağılıkları Şekil 7 'de sunulmuştur.
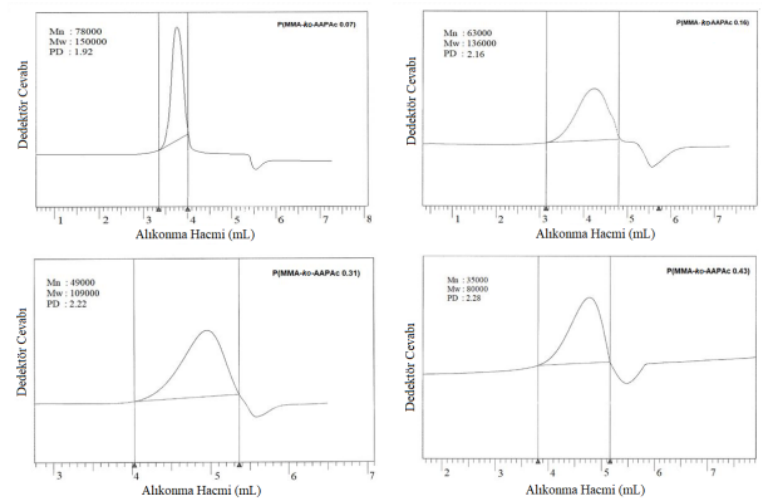

Şekil 7. GPC curves of the P(MMA-ko-AAPAc)

P(MMA-ko-AAPAc)'nın ortalama moleküler ağırlı̆̆ı, kopolimer sistemdeki AAPAc birimlerinin içeriği arttıkça azalmaktadır. $\mathrm{Bu}$ azalmanın, AAPAc ünitelerindeki zincir transfer reaksiyonlarındaki artıştan kaynaklandığı düşünülmektedir.

\subsection{Polimerlerin Termal Davranışı}

\subsubsection{DSC ölçümleri}

Kopolimerlerin termal özellikleri göz önüne alındığında, polimerler için önemli özellik olan camsı geçiş sıcaklığına (Tg) dikkat çekmek gerekir. Plastiğin 1sitıldıktan sonra hızla soğuduğunda sertleşip kırılgan hale geldiği sıcaklığa camsı geçiş sıcaklığı denir [11]. Camsı geçiş sıcaklığında, polimer zincirlerini birbirine bağlayan zayıf ikincil bağlar kopar ve makromolekül hareket etmeye başlar. $\mathrm{Bu}$ sicaklık (Tg), polimerin segmental zincir hareketliliğini anlamak için çok önemli ve karakteristiktir $[12,13]$.

Kopolimerlerin Tg değerleri DSC'den elde edilen eğrilerden belirlendi. Kopolimerlerin DSC analizleri oda sıcaklığından $200{ }^{\circ} \mathrm{C}^{\prime}$ ye kadar azot atmosferi altında 20 ${ }^{\circ} \mathrm{C} /$ dakika isıtma hızında ölçüldü. Kopolimerlerin DSC eğrileri Şekil 8'de gösterilmektedir. Şekil 8'de görüldüğü üzere DSC eğrileri homojen fazlardır ve iki monomerin birbiriyle uyumlu olduğu anlamına gelir. Kopolimer bileşiminde AAPAc birimlerinin konsantrasyonu arttıkça Tg'de bir artış gözlendi. Tg, P(MMA-ko-AAPAc 0.07) kopolimeri için $123^{\circ} \mathrm{C}$ ve P(MMA-ko-AAPAc 0.43 ) için $142{ }^{\circ} \mathrm{C}^{\prime}$ dir. $\mathrm{Bu}$ davranış, muhtemelen, kopolimerin serbest hacmindeki azalmadan kaynaklanmaktadır. $\mathrm{Bu}$ durum zincirlerin hareketliliğini azaltır ve sonuç olarak cam geçiş sıcaklığı artar.

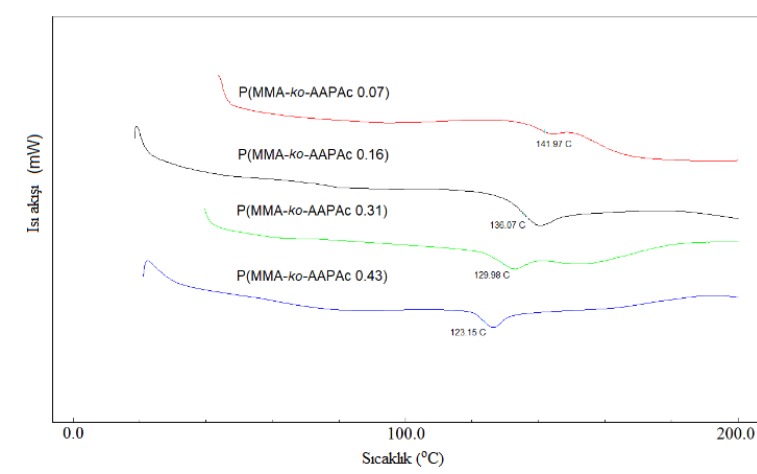

Şekil 8. Kopolimerlerin DSC eğrileri

\subsubsection{Termogravimetrik analiz (TGA)}

Termogravimetrik analiz (TGA), polimerik sistemlerin termal stabilitesini araştırmak için en uygun yöntem olarak bilinir [14]. TGA, kontrollü bir atmosfer altında numune ağırlığındaki değişiklikleri zaman ve sıcaklığın bir fonksiyonu olarak izleme imkânı verir. Elde edilen termogramlardaki ağırlık değişiklikleri genellikle reaksiyon kinetiği, ayrışma, kimyasal ve fiziksel parametrelerle ilişkilidir [15]. Kopolimerlerin termogravimetrik analizi, Shimadzu TGA-50 kullanılarak gerçekleştirildi. Yaklaşı $5 \mathrm{mg}^{\prime} \mathrm{l} \mathrm{k}$ numuneler bir platin numune kabina konuldu ve $10{ }^{\circ} \mathrm{C}$ $\mathrm{dk}^{-1}$ isitma hizında oda sicaklığından azot atmosferi altında $600{ }^{\circ} \mathrm{C}^{\prime}$ ye 1 sitıldı. Şekil 9 (a), serbest radikal polimerizasyon yöntemi ile hazırlanan kopolimerlerin karşılaş̧ırmalı olarak TG termogramlarını gösterir.
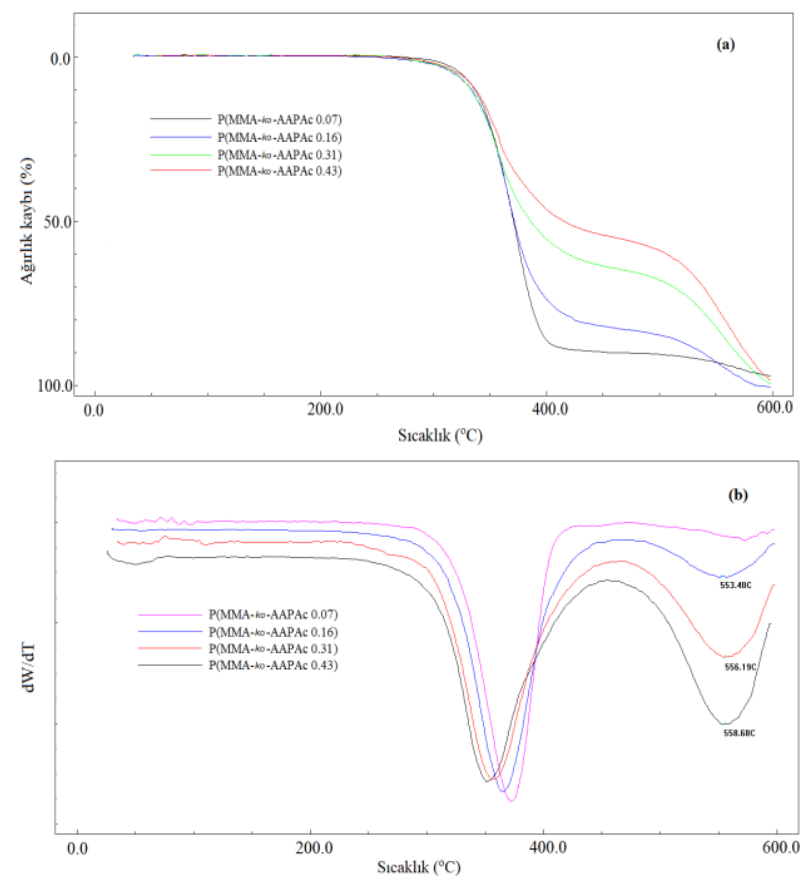

Şekil 9. Kopolimerin a) TGA b) D-TGA eğrileri

Kopolimerlerin TGA sonuçları Tablo 3 'te özetlenmiştir. Kopolimerlerin ilk ayrışma sıcaklıkları $\left(\mathrm{T}_{\text {baş }}\right)$ önemli ölçüde değişmezken, AAPAc birimi arttıkça \% 50 kütle kaybına karşıllık gelen sıcaklıkta önemli bir artış olduğu görülmüştür. 
Tablo 3. Kopolimer serisinin termal özellikleri

\begin{tabular}{|c|c|c|c|c|c|}
\hline Kopolimer & $\begin{array}{l}\mathbf{T}_{\mathrm{g}}\left({ }^{\circ}\right. \\
\mathbf{C})\end{array}$ & $\begin{array}{l}\mathbf{T}_{\text {bas }} \\
\left({ }^{\circ} \mathrm{C}\right)\end{array}$ & $\begin{array}{l}\mathbf{T}_{\% 50} \\
\left({ }^{\circ} \mathrm{C}\right)\end{array}$ & $\begin{array}{c}500{ }^{\circ} \mathrm{C} \\
\text { deki } \\
\% \text { Atık }\end{array}$ & $\begin{array}{c}\text { Tmax } \\
\text { (in D-TG) }\end{array}$ \\
\hline $\begin{array}{l}\text { P(MMA-ko- } \\
\text { AAPAc } 0.07)\end{array}$ & 123 & 319 & 363 & 10 & 373 \\
\hline $\begin{array}{l}\text { P(MMA- } k o- \\
\text { AAPAc } 0.16)\end{array}$ & 130 & 315 & 364 & 18 & 366 \\
\hline $\begin{array}{l}\text { P(MMA-ko- } \\
\text { AAPAc } 0.31)\end{array}$ & 136 & 316 & 382 & 33 & 357 \\
\hline $\begin{array}{l}\text { P(MMA-ko- } \\
\text { AAPAc } 0.43)\end{array}$ & 142 & 318 & 421 & 42 & 350 \\
\hline
\end{tabular}

P(MMA-ko-AAPAc 0.07) için \% $\mathrm{T}_{50}$ sıcaklığının $363{ }^{\circ} \mathrm{C}$ ve $\mathrm{P}$ (MMA-ko-AAPAc 0.43) için $421{ }^{\circ} \mathrm{C}$ olduğu belirlendi. Bu sonuçlara göre, kopolimerdeki AAPAc birimlerinin oranı arttıkça, polimer termal stabilite kazanır. Kopolimer serisinin TGA termogramları, iki aşamalı bir termal ayrışmayı ifade eder. İlk adım, zincir kırılmalarına yol açan PMMA'nın depolimerizasyonunu içerir. İkinci adım, kopolimerdeki antrasen içeriğinin artmasıyla daha net gözlenir. Bu davranışın nedeninin, ilk adımda başlayan zincir kırılmalarının yanı sıra AAPAc ünitesindeki antrasen grubunun ayrışmasından kaynaklandığı düşünülmektedir. Kopolimer sistem için $500{ }^{\circ} C^{\prime}$ deki artık miktarları \%10'dan \%42'ye kadar değişmektedir. Kopolimerlerin türev eğrileri (D-TG) Şekil 9(b) 'de gösterilmektedir. Kopolimer sistemde AAPAc ünitelerinde artışla birlikte kopolimerin maksimum bozunma sıcaklıkları (Tmax) $373{ }^{\circ} \mathrm{CC}^{\prime} \mathrm{den} 350$ ${ }^{\circ} \mathrm{C}^{\prime}$ ye düşmüştür.

\subsection{Kopolimerlerin Dielektrik Özellikleri}

Dielektrik özelliklerin belirlenmesinde Empedans analizi tekniği bu amaçla kullanılan en yaygın metottur [16]. Belirlenen frekans aralığı için kapasitans (Cp), kayıp faktörü (DF), iletkenlik (Gp) değerleri kaydedilir ve sırasıyla dielektrik sabiti $\left(\varepsilon^{\prime}\right)$, dielektrik kayıp faktörü $\left(\varepsilon^{\prime \prime}\right)$, AC iletkenlik $\left(\sigma_{\mathrm{ac}}, \mathrm{S} / \mathrm{cm}\right)$ değerleri aşağıdaki denklemler (1-3) [17] kullanılarak hesaplanır.

$\varepsilon^{\prime}=C_{p} \frac{d}{A \varepsilon_{0}}$

Burada "Cp" kapasitans, " $\varepsilon_{\mathrm{o}}$ " boşluğun dielektrik sabiti $\left(\varepsilon_{\mathrm{o}}=8.854 \times 10^{-12} \mathrm{~F} / \mathrm{m}\right)$, "d" polimer örneğinin et kalınlığ 1 ve "A" numunenin alanını ifade eder.

$\varepsilon^{\prime \prime}=\varepsilon^{\prime} \mathrm{DF}$

$\sigma=\mathrm{G}_{\mathrm{p}} \frac{\mathrm{d}}{\mathrm{A}}$

Burada $d$ et kalınlığı, Gp konduktans ve A numunenin alanı $\left(\mathrm{cm}^{2}\right)$. Dielektrik sabiti, malzemenin polarlanabilirliğinin bir ölçüsüdür. Bir elektrik alanı altında malzemede kalıcı dipol oluşumundan kaynaklanan yönelim polarizasyonu ve moleküler polarizasyondan kaynaklanan elektronik ve iyonik polarizasyon, dielektrik sabitini belirleyen ana faktörlerdir. Kopolimerdeki antrasen birimlerinin artmasının dielektrik özellikler üzerindeki etkisini araştırmak için $\varepsilon$ ', $\varepsilon^{\prime \prime}, \sigma_{\mathrm{ac}}$ değerleri Şekil 10'da karşılaştırmalı olarak gösterilmiştir.
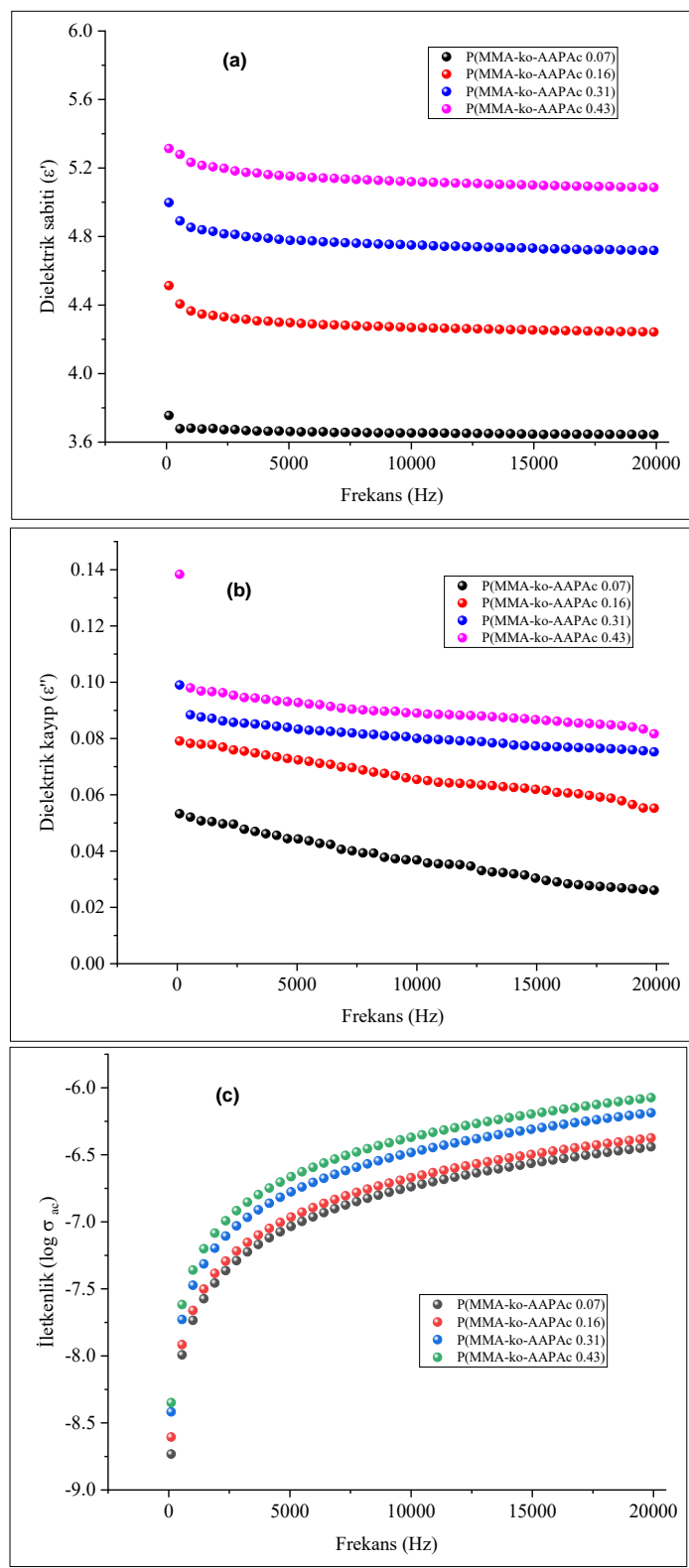

Şekil 10. Saf kopolimerlerin a) $\varepsilon$ ', b) $\varepsilon$ " ve c) $\delta_{\text {ac }}$ değerlerinin frekansla değişim

Dielektrik sabiti ve dielektrik kayıp değerleri, artan frekansla azalmıştır [18]. Bunun nedeni, yönelim ve arayüz polarizasyonunun düşük frekans değerlerinde daha aktif olmasıdır. Dielektrik kayıp değerlerinde de benzer davranış gözlemlendi. Bu çalışmadaki en çarpıcı sonuç, kopolimerde antrasen ve konjuge kalkon grubu içeren AAPAc birimlerinin oranı arttıkça dielektrik özelliklerinin önemli ölçüde artmasıdır. 1 kHz'de 25 ${ }^{\circ} \mathrm{C}$ 'de dielektrik sabiti P(MMA-ko-AAPAc 0.07) kopolimeri için 3.68 iken P(MMA-ko-AAPAc 0.43) kopolimeri için 5.21 idi. $\mathrm{Bu}$ artışın, AAPAc birimlerindeki kalkon ve antrasen gruplarının oluşturduğu $\pi$-konjugasyonundan kaynaklandığı düşünülmektedir. Polimerlerin dielektrik özellikleri, monomerin yapısındaki polar gruplar ve konjugasyon ile ilişkilidir [19]. Kopolimer serisinin dielektrik özellikleri Tablo 4'te özetlenmiştir. 
Tablo 4. Kopolimer serisinin $1 \mathrm{kHz}$ ve $25^{\circ} \mathrm{C}$ deki dielektrik özellikleri

\begin{tabular}{lccc}
\hline Kopolimer & $\boldsymbol{\varepsilon}^{\prime}$ & $\boldsymbol{\varepsilon}^{\prime \prime}$ & $\boldsymbol{\sigma ( S / \mathbf { c m } )}$ \\
\hline P(MMA-ko-AAPAc 0.07) & 3.68 & 0.050 & $2.39 \times 10^{-8}$ \\
P(MMA-ko-AAPAc 0.16) & 4.35 & 0.077 & $2.83 \times 10^{-8}$ \\
P(MMA-ko-AAPAc 0.31) & 4.84 & 0.087 & $4.36 \times 10^{-8}$ \\
P(MMA-ko-AAPAc 0.43) & 5.21 & 0.096 & $5.66 \times 10^{-8}$ \\
\hline
\end{tabular}

Saf kopolimerlerin ve kopolimer kompozitlerin dielektrik özellikleri, polar grubun yük dağılımının termal hareketi ile belirlenir. Dielektrik davranış, yönelme, iyonik ve elektronik polarizasyon nedeniyle oluşur. Antrasen birimleri içeren kopolimer serisinin elektriksel özelliklerine etkisini anlamak için \% 4 nanografen içeren kompozitler hazırlanmıştır. Kompozitlerin dielektrik ölçümleri $100 \mathrm{~Hz}-20 \mathrm{kHz}$ frekans aralığında kaydedildi ve Şekil 11'de karşılaştırmalı olarak gösterildi. Şekil 11 'de gösterildiği gibi, dielektrik sabiti \%4 nanografen eklenmesiyle büyük ölçüde arttı. $\mathrm{Bu}$ davranış, elektrik alanı yönündeki dipollerin sayısındaki artıştan kaynaklanmaktadır. $\mathrm{Bu}$ artışın nedeni, kopolimerin yan grubuna bağli olan antrasen ve kalkon gruplarının nanografen ve $\pi$ bağları ile daha kolay etkileşmesidir. Literatürdeki diğer çalışmalarda da benzer davranışlar rapor edilmiştir $[20,21]$. Kopolimer serisinin \%4 grafen kompozitlerinin $25{ }^{\circ} \mathrm{C}$ ve $1 \mathrm{kHz}$ 'de dielektrik ve elektriksel özellikleri Tablo 5 'te özetlenmiştir.

Tablo 5. Kopolimer serisinin $\% 4$ grafen kompozitlerinin $25^{\circ} \mathrm{C}$ ve 1 kHz'de dielektrik ve elektriksel özellikleri

\begin{tabular}{lccc}
\hline Kopolimer kompozit & $\boldsymbol{\varepsilon}^{\prime}$ & $\boldsymbol{\varepsilon}^{\prime \prime}$ & $\boldsymbol{\sigma ( S / \mathbf { c m } )}$ \\
\hline P(MMA-ko-AAPAc 0.07) & 23.43 & 82.7 & $5.44 \times 10^{-8}$ \\
P(MMA-ko-AAPAc 0.16) & 64.26 & 926.6 & $6.70 \times 10^{-7}$ \\
P(MMA-ko-AAPAc 0.31) & 144.21 & 5131.8 & $3.28 \times 10^{-6}$ \\
P(MMA-ko-AAPAc 0.43) & 273.28 & 9604.62 & $1.04 \times 10^{-5}$ \\
\hline
\end{tabular}

Kopolimer serisinde en yüksek dielektrik sabiti değeri, en çok AAPAc birimini içeren P(MMA-ko-AAPAc 0.43) kopolimeri olarak belirlenmiştir. Düşük grafen konsantrasyonunda dielektrik sabitindeki yüksek bir artış, P(MMA-ko-AAPAc)'nin fonksiyonel grupları (kalkon-antrasen) ile grafen partikülleri arasındaki indüklenmiş dipol-indüklenmiş dipol veya londonlondon fiziksel etkileşimlerinin olduğunu gösterir.

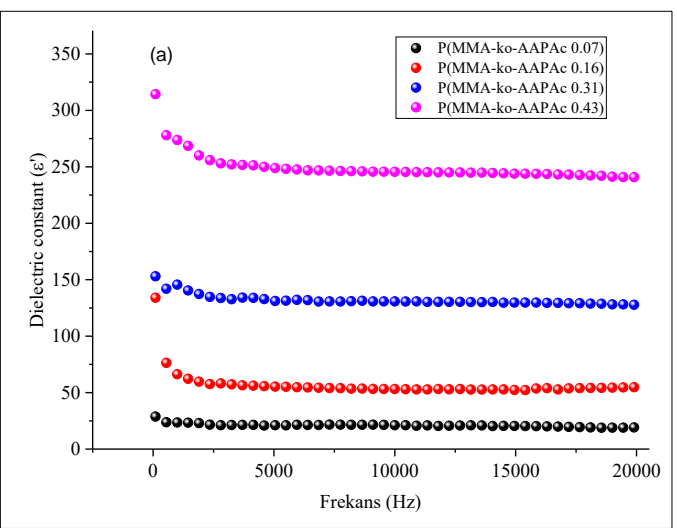

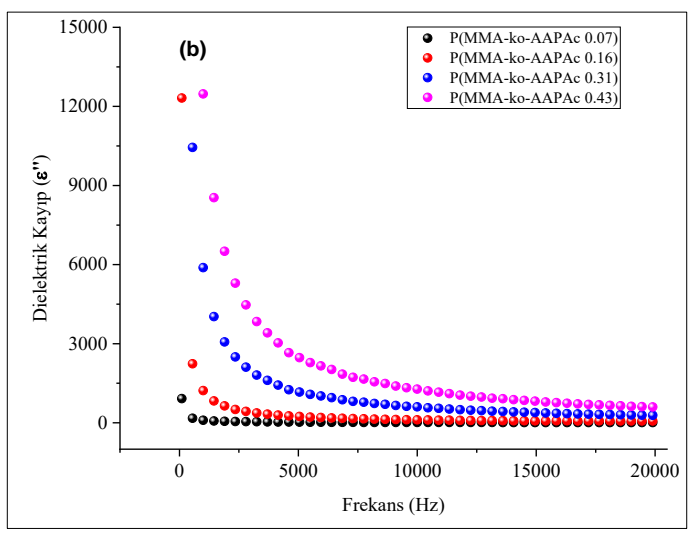

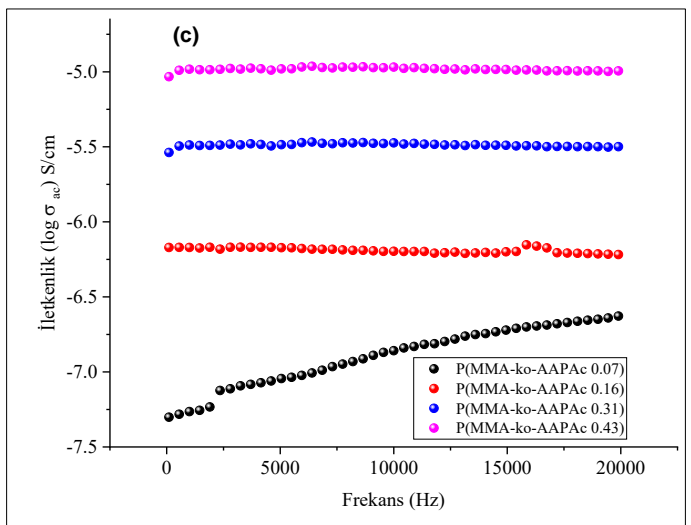

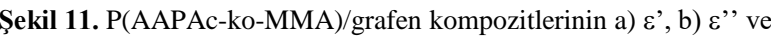
c) $\delta_{\text {ac }}$ değerlerinin frekansla değişim

Kopolimer / grafen kompozitlerinin alternatif iletkenlik $\left(\sigma_{\mathrm{ac}}\right)$ değerleri frekansa karşı ölçüldü. Elde edilen sonuçlara göre, sabit bir sicaklıkta $\sigma_{\mathrm{ac}}$ artan frekansla arttığ 1 belirlenmiştir. P(MMA-ko-AAPAc 0.43$) \quad \sigma_{\mathrm{ac}}$ değeri, $1 \mathrm{kHz}$ ve oda sicaklığında $5.66 \times 10^{-08} \mathrm{~S} / \mathrm{cm}$ 'den $1.04 \times 10^{-05} \mathrm{~S} / \mathrm{cm}^{\prime}$ ye yükselmiştir. En çok AAPAc birimini içeren P(MMA-ko-AAPAc 0.43) kopolimer kompoziti için yüksek iletkenlik $\left(\sigma_{\mathrm{ac}}\right)$ değeri, iyi arayüzey etkileşiminden ve kopolimer ile grafen arasındaki elektronik ve dipol polarizasyonundaki artıştan kaynaklanmış olabilir.

\subsection{Kompozitlerin Elektriksel Özellikleri}

Kompozitlerin yarı iletken özellikler gösterdiğini belirlemek için DC iletkenlik değerleri sıcaklığın bir fonksiyonu olarak ölçüldü. Kompozitler oda sıcaklığından $100{ }^{\circ} \mathrm{C}^{\prime}$ ye sabit bir 1sitma hizında kapalı firında 1sıtıldı. Ölçüm sırasında kompozitlere sabit voltaj (2V) uygulandı. Artan sicaklıkla DC iletkenlik değerinin doğrusal artışı, hazırlanan kompozitlerin yarı iletken özelliklere sahip olduğunun önemli bir kanıtıdır [22]. Kopolimerler için optimum grafen içeriğini belirlemek için ön deneyler yapıldı. Bu deneylerde, kompozitler ağırlıkça \% 1 ve\% 2 grafen kullanılarak hazırlanmış ve DC iletkenlik ölçülmüștür. Ancak, hazırlanan bu oranlar için kompozitlerde beklenen yarı iletken özellikler oluşmadı. $\mathrm{Bu}$ nedenle tüm kopolimer kompozitlerde grafen içeriği ağılıkça\% 4 olarak seçilmiştir. Kompozitlerin aktivasyon enerjisi (Ea) aşağıdaki denklem (4) ile hesaplanır: 
$\sigma(w)=\sigma_{0} \exp \left(\frac{-\Delta E_{a}}{k_{B} T}\right)$

$\mathrm{Bu}$ denklemde, "Ea" ile sembolize edilen aktivasyon enerjisi, "kB" ile sembolize edilen Boltzmann sabiti, " $\sigma_{\mathrm{o}}$ " ile sembolize edilen ön üstel faktör, "T" ile sembolize edilen mutlak sıcaklıktır. 1/T'ye karşı ln $\sigma$ değerleri çizilerek elde edilen doğrunun eğimi aktivasyon enerjisi olarak alınır [23].
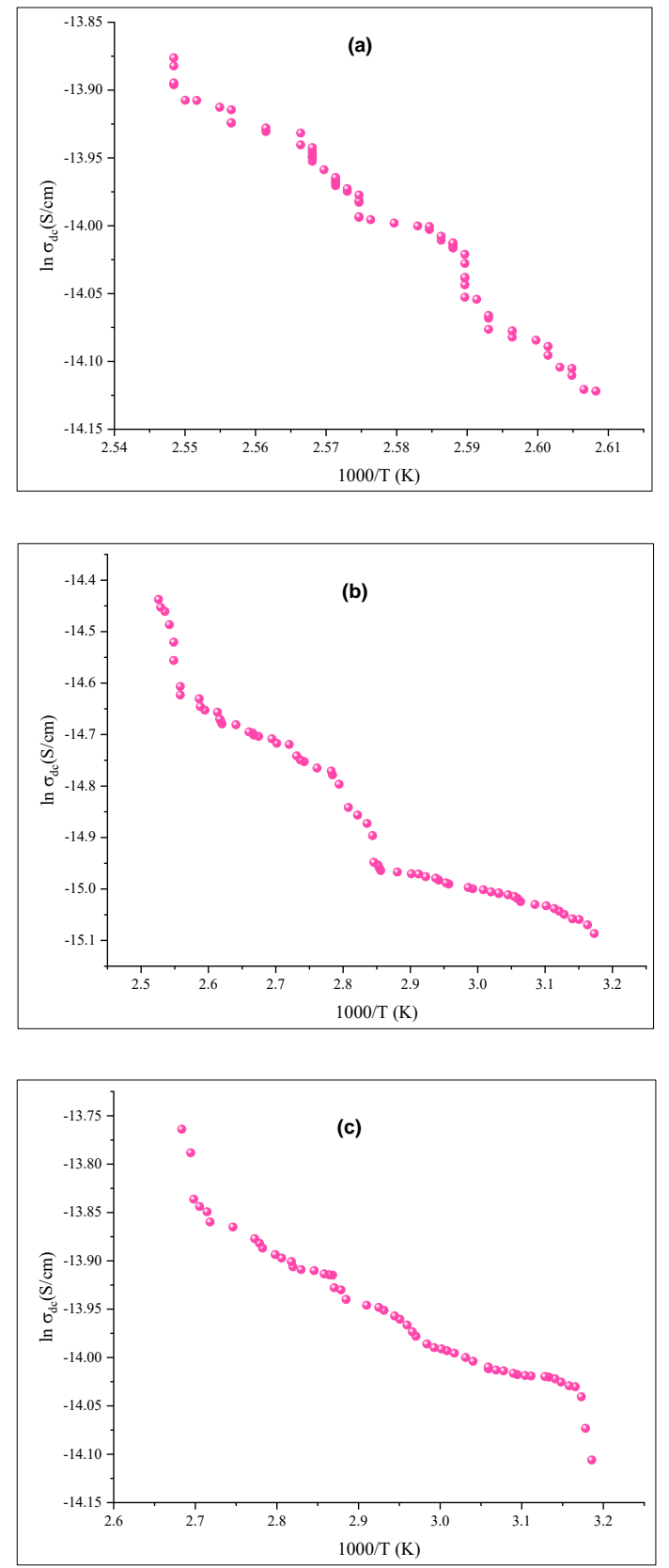

Şekil 12. \%4 grafen içeren kopolimer kompozitlerinin a) P(MMA-koAAPAc 0.16), b) P(MMA-ko-AAPAc 0.31) ve c)P(MMA-ko-AAPAc $0.43)$ dc iletkenliğinin sıcaklıkla değișimi

Şekil 12'de görüldüğü gibi, kopolimer/grafen kompozitler için 1000/T'ye karşı iletkenlik verilmiştir. P(MMA-ko-AAPAc 0.16), P(MMA-ko-AAPAc 0.31) ve P(MMA-ko-AAPAc 0.43) aktivasyon enerji değerleri sirasiyla $0.320,0.077$ ve $0.040 \mathrm{eV}^{\prime}$ dir.

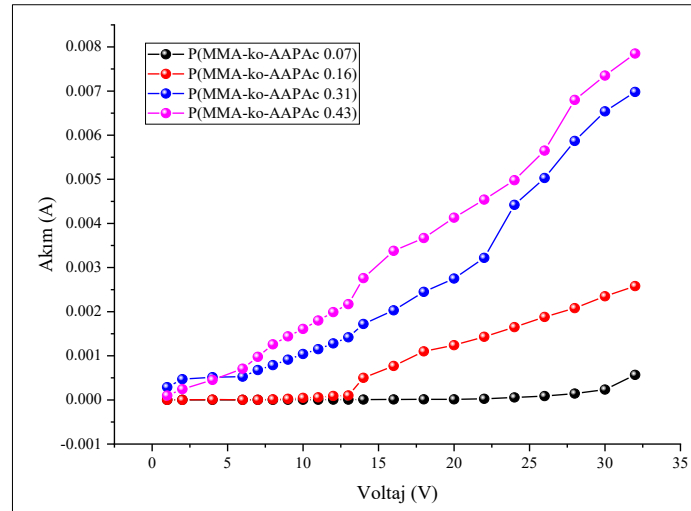

Şekil 13. Grafen kompozitlerin oda sıcaklığındaki I (akım)-Voltaj (V) eğrileri

Grafen kompozitlerin oda sıcaklığındaki I (akım)-Voltaj (V) eğrileri Şekil 13'de gösterilmektedir. Sabit voltajda kopolimer kompozit sistemlerde AAPAc içeriği arttıkça akım önemli ölçüde artmıştır [24].

\section{SONUÇ}

$\mathrm{Bu}$ çalışmada ilk olarak antrasen içeren hidroksi kalkon bileşiği ile yeni bir akrilat monomeri (AAPAc) sentezlendi. $\mathrm{Bu}$ monomer ile MMA monomeri kullanılarak serbest radikalik polimerizasyon yöntemine göre bir kopolimer serisi hazırlandı. Tüm yapılar FT-IR, ${ }^{1} \mathrm{H}-\mathrm{NMR}$ ve ${ }^{13} \mathrm{C}$-NMR teknikleri kullanılarak karakterize edildi. Kopolimere kütlece $\% 4$ oranında grafen katkılanarak kompozitler hazırland1. Bu kompozitlerin elektriksel özellikleri frekans ve sicaklığın bir fonksiyonu olarak incelendi: Sonuç olarak $\% 4$ grafen ilavesi ile elektriksel özelliklerinde dikkat çekici bir artış gözlendi. Kopolimer/grafen kompozitlerinin aktivasyon enerji değerleri, sıcaklığın bir fonksiyonu olarak DC iletkenliği ölçülerek belirlendi. Aktivasyon enerjisi değerleri P(MMA-ko-AAPAc 0.16), P(MMA-koAAPAc 0.31) ve P(MMA-ko-AAPAc 0.43) için sırasıyla $0.320,0.077$ ve $0.040 \mathrm{eV}$ olarak hesaplandı. Bu sonuçlar Tablo 6'da özetlenmiştir.

Tablo 6. Kopolimer/4\% grafen kompozitlerin Aktivasyon enerji değerleri

\begin{tabular}{llll}
\hline Kopolimer/grafen kompozit & Eğim & k & Ea (eV) \\
\hline P(MMA-ko-AAPAc 0.16) & 3.788 & 0.086 & 0.320 \\
P(MMA-ko-AAPAc 0.31) & 0.898 & 0.086 & 0.077 \\
P(MMA-ko-AAPAc 0.43) & 0.466 & 0.086 & 0.040
\end{tabular}

Aktivasyon enerjileri değerlendirildiğinde, grafenantrasen konsantrasyonuna bağlı olarak birden fazla iletim mekanizması önerilebilir. Elektronik iletim, nispeten yüksek hareketlilik ve düşük Ea değeri ile tanımlanırken, iyonik iletim, yüksek Ea değerleri ve düşük hareketlilik ile karakterize edilir. Bu çalışmadaki Ea değerlerinin 0,8 eV'nin altında olduğu belirlenmiştir. Dolayısıyla elektronik iletim olarak kabul edilir [25].

\section{KAYNAKLAR}

[1] Jones RN. The ultraviolet absorption spectra of anthracene derivatives. Chem Rev, 41:1947:35371. 
[2] Dadvand A, Sun WH, Moiseev AG, BelangerGariepy F, Rosei F, Meng H, et al.1,5-, 2,6-and 9,10-distyrylanthracenes as luminescent organicsemiconductors. J Mater Chem C, 1: 2013:2817-25.

[3] Zhao Y, Yan L, Murtaza I, Liang X, Meng H, Huang W. A thermally stableanthracene derivative for application in organic thin film transistors. Org Electron, 43: 2017:105-11.

[4] Hisamatsu S, Masu H, Takahashi M, Kishikawa K, Kohmoto S. Pairwisepacking of anthracene fluorophore: hydrogen-bonding-assisted dimeremission in solid state. Cryst Growth Des, 15: 2015:2291-302.

[5] Song JY, Park SN, Lee SJ, Kim YK, Yoon SS. Novel fluorescent blue-emittingmaterials based on anthracene-fluorene hybrids with triphenylsilane groupfor organic light-emitting diodes. Dyes Pigm, 114: 2015:40-6.

[6] Chen M, Zhao Y, Yan L, Yang S, Zhu Y, Murtaza I, et al. A unique blend of 2-fluorenyl-2-anthracene and 2-anthryl-2-anthracence showing whiteemission and high charge mobility. Angew Chem Int Ed, 56: 2017:722-7

[7] Krakovyak MG, Anufrieva EV, Lushchık VB, Shelekhov NS, Skorokhodov SS. 9Anthryldiazomethane in the Synthesis of Anthracene- Containing Polymers. J Macromol Sci: Part A-Chem, 12: 1978:789-814.

[8] Skorokho SS, Krakovyak MG, Anufrieva EV, Shelekhov NS. Investigation of chemical behavior of anthracene derivatives as monomers and reagents in synthesis of macromolecules containing anthracene groups. J Polym Sci, 42: 1973:1229-38.

[9] Krakovyak MG, Anufrieva YV, Skorokho SS. Synthesis and copolymerization of anthracenecontaining acrylic monomers. Polym Sci USSR, 14(5): 1972:1259-64.

[10] Modzelewska A, Pettit C, Achanta G, Davidson NE, Huang P, Khan SR. Anticancer activities of novel chalcone and bis-chalcone derivatives. Bioorganic \& Medicinal Chemistry, 14: 2006; 3491-95.

[11] P. Dallas, V. Georgakilas, D. Niarchos, P. Komninou, T. Kehagias, D. Petridis. Synthesis, Characterization and Thermal Properties of Polymer/Magnetite

Nanotechnology, 17: 2006: 2046-53.

[12] Biryan F, Demirelli K. Copolymerization of Benzyl Methacrylate and a Methacrylate Bearing, Benzophenoxy and Hydroxyl Side Groups: Monomer Reactivity Ratios, Thermal Studies and Dielectric Measurements. Fibers and Polymers, 18: 2017:1629-37.

[13] Mano JF, Koniarova D, Reis RL. Thermal properties of thermoplastic starch/synthetic polymer blends with potential biomedical applicability. J Mat Sci: Mat in Med, 14: 2003:12735.

[14] Gama NV, Silva R, Mohseni F, Davarpanah A, Amaral VS, Ferreiraad A, Barros-Timmons A. Enhancement of physical and reaction to fire properties of crude glycerol polyurethane foams filled with expanded graphite. Polym Test, 69: 2018:199-207.

[15] Biryan F, Demirelli K. Characterization, thermal behavior, and electrical measurements of poly[4-(2bromoisobutyroyl methyl)styrene]. Adv Polym Teghnol, 37: 2017:1994-2012.

[16] Zheng W, Wong SC. Electrical conductivity and dielectric properties of PMMA/expanded graphite composites. Comp Sci Technol, 63: 2003: 225-35.

[17] Xiang H, Zheng Z, Guang-Xin C, Qifang L. Composite material with high dielectric constant and low dielectric loss obtained through grafting of cyano groups in imidazolium ionic liquids. Chem Phys Lett, 711: 2018:173-77.

[18] Ningaraju S, Vinayakaprasanna NH, Gnana Prakash AP, Ravikumar HB. Free volume dependence on electrical properties of Poly (styrene co-acrylonitrile)/Nickel oxide polymer nanocomposites. Chem Phys Lett, 698: 2018:24-35.

[19] Tahaa TA, Azabb AA. Thermal, optical, and dielectric investigations of PVC/La0.95Bi0.05FeO3 nanocomposites. J Mol Str, 1178: 2019:39-44.

[20] Uyor UO, Popoola API, Popoola OM, Aigbodion VS. Enhanced dielectric performance and energy storage density of polymer/ graphene nanocomposites prepared by dual fabrication. J Thermoplast Comp Mat, 2018:1-16.

[21] Koran K. Structural, chemical and electrical characterization oforganocyclotriphosphazene derivatives and their graphene-basedcomposites. J Mol Str, 1179: 2019:224-32.

[22] Sudha LK, Sukumar R, Uma Rao K. Evaluation of activation energy (Ea) profiles of nanostructured alumina polycarbonate composite insulation materials. Int J Mater Mech Manuf, 2(1): 2014; p:1973-8198.

[23] Rhoderick, E.H., Williams, R.H., 1988. MetalSemiconductor Contacts, 2nd ed. Clarendon Press, Oxford, s45-50.

[24] Pham H, Tran HN, Holland AS, Partridge JG. Temperature-Dependent Electrical Characteristics and Extraction of Richardson Constant from Graphitic-C/n-Type 6H-SiC Schottky Diodes. J Elec Mat, 48: 2019:2061-2066.

[25] Jonscher AK. Electronic properties of amorphous dielectric films, Thin Solid Films, 1(3): 1967:213234. 